\title{
Examining Shades of Grey with Students: Social Justice Education in Action
}

Darren E. Lund

Follow this and additional works at: https://digitalscholarship.unlv.edu/jpme

\section{Repository Citation}

Lund, Darren E. (2011) "Examining Shades of Grey with Students: Social Justice Education in Action," Journal of Praxis in Multicultural Education: Vol. 6: No. 1, Article 9.

DOI: 10.9741/2161-2978.1055

Available at: https://digitalscholarship.unlv.edu/jpme/vol6/iss1/9

This Article is protected by copyright and/or related rights. It has been brought to you by Digital Scholarship@UNLV with permission from the rights-holder(s). You are free to use this Article in any way that is permitted by the copyright and related rights legislation that applies to your use. For other uses you need to obtain permission from the rights-holder(s) directly, unless additional rights are indicated by a Creative Commons license in the record and/ or on the work itself.

This Article has been accepted for inclusion in Journal of Praxis in Multicultural Education by an authorized administrator of Digital Scholarship@UNLV. For more information, please contact digitalscholarship@unlv.edu. 


\title{
Examining Shades of Grey with Students: Social Justice Education in Action
}

\begin{abstract}
Darren E. Lund
The researcher undertook a critical examination of an innovative social justice education course being piloted at an urban high school in the prairie region of western Canada. The research involved observations, conversations, document analysis, and in-depth interviews with a small number of students and teachers, in order to analyze the daily experiences, challenges, and successes of a group of students and teachers who have undertaken to address issues of discrimination, social justice, and human rights in their school. This research links ongoing academic and school work by focusing attention on the experiences of a specific group of students and their teachers in a unique and promising social justice education program. Findings point to a number of strengths of the course, including the comprehensive nature of the information surveyed, the strong theme of student involvement, the passion and commitment of the teachers, their honoring the complexity of understanding current social justice issues, the appropriateness of the course to student interests and strengths, the inquiry approach taken by the teachers, and the daily use of technology and the Internet in their learning.
\end{abstract}

This study ${ }^{1}$ builds on the researcher's recent research with student activists (Lund, 2008b; Lund \& Nabavi, 2008) by studying a specific social justice program in a Canadian school setting. The study included numerous school visits, interviews, observations, and in-depth interviews with eight student and teacher activists focused on a critical examination of an innovative social justice education program at an urban high school in Canada's prairie region. The researcher has sought to better understand the daily experiences, challenges, and successes of a small group of students and teachers who have undertaken to address issues of racism and discrimination in their school.

This study sought to add depth to our understanding of the roles that teachers and students can play as agents of change and complement other school-based social justice research contributing to policy and programming

Dr. Darren E. Lund earned his Ph.D. in anti-racism and multicultural education at the University of British Columbia, and he has been named a Reader's Digest National Leader in Education. He has published widely in the field of social justice activism and teacher education, with a focus on student and teacher collaborative projects. For sixteen years Darren taught high school in Alberta, Canada, where he founded and advised the multiple award-winning Students and Teachers Opposing Prejudice (STOP) Program. He is Professor in the Faculty of Education at the University of Calgary in Calgary, Alberta and is involved with a number of ongoing social justice projects and community organizations. 
associated with growing school diversity. Of particular benefit to educational policymakers will be a better understanding and analysis of the complex nature of how students and teachers form and sustain social justice work and actually make use of web-based materials to establish and sustain educational projects in schools and communities. Educational policymakers for anti-racism and multicultural education at the school, district, as well as state and provincial levels may benefit from a more fully developed analysis of the experiences of those in school settings.

The study's funder was the Metropolis Project, and the following Metropolis "policy priority" statements served as guiding inquiry topics for this study: a) What is the role of schools in creating a sense of community? b) What effective strategies have been developed to counter racism and discrimination? These two questions appear within a federal research policy document and I include them here as overarching themes that have shaped my understanding of this work. Both inform the larger backdrop of undertaking diversity work in schools and communities. I add a third question: c) How can teachers best create educational experiences to engage students meaningfully in the in-depth study of social justice issues, and how may these experiences lead to activism for social change?

Some more specific guiding research questions included: 1) How do teachers and students conceptualize and articulate social justice education and activism? 2) What are some of the intersections of existing social justice research and the understandings of school-based social justice education? and 3) How might these understandings, based on the lived experiences of current students and teachers in an innovative social justice course, inform research, policies, and programming? From the outset, the researcher positioned the pilot study as a vehicle both for facilitating and evaluating social justice activism and an instrument of community building among committed teachers and students. The current study offers a closer look at one social justice program in one school, but hopefully may provide impetus for further and broader research in innovative school curriculum and programming.

\section{Context and Background}

The increasingly diverse population in Canada, as in other Western nations, poses various challenges and opportunities that deserve our serious attention. Educators deal on a daily basis with individual differences defined by racial, gender, cultural, and economic factors as well as access and "disparities in the distribution of educational resources" (Cochran-Smith, 2004). Rather than looking at the growing diversity in public schools as a source of tension and discord, the proactive educational approach studied in this project builds on best practices. Neito (2003) reminds us that multicultural education cannot simply be 
an add-on component to a school, but needs to be accompanied by a deep commitment to social justice and equal access to resources-education that addresses equity for all. Social justice education for the purposes of this study may include educational activities, lessons, school or community displays, guest speakers, group activities, awareness events, media campaigns, and other collective engagement of students and teachers on issues of race, difference, and ethnicity, among other diversity and equity issues.

Deliberately placing social justice education within a human rights framework has not been the norm in the U.S. literature on multicultural education, but is an approach favored in much diversity work in education in Canada, Britain, and Europe (Gillborn, 2005; Joshee, 2003; Luchtenburg, 2003; Watkinson, 1999). Further, a landmark international publication on diversity and democracy in the global context (Banks et al., 2005) seeks to highlight the human rights core of diversity work, asserting that,

only when a nation-state is unified around a set of democratic values such as human rights, justice, and equality can it secure the liberties of cultural, ethnic, language, and religious groups and enable them to experience freedom, justice, and peace. (p. 7)

For this study I adopted a theoretical stance that recognizes intersections across issues of race, ethnicity, class, gender, sexual orientation and other elements of social identity (e.g., Dei \& Calliste, 2000). Much curricular material has been developed in recent years to help teachers reflect and honor cultural diversity in teaching materials and practices (James, 2005; Kumashiro, 2009; Nieto \& Bode, 2007; Solomon \& Levine-Rasky, 2003). Developing proactive educational approaches to promote equity and fairness is seen as part of teachers' responsibility to support students in reaching their full potential. Amongst various educational stakeholders, teachers are vitally important in promoting educational equity (Armstrong \& McMahon, 2006; Sleeter, 1996). Many teachers, however, have not been well prepared to face these challenges in relation to diversity (Gorski, 2004; Kumashiro, 2009). This research links ongoing academic and school work by focusing attention on the experiences of a specific group of students and their teachers in a unique and promising social justice education program.

\section{School Context}

This study took place within the context of a charter school, but in the particular jurisdiction of Alberta, these schools are funded by public dollars and are not allowed to charge tuition. It is significant that, since 1994, the numbers of private schools, charter schools, and public magnet schools have increased 
significantly (Alberta Education, 2007). By 2001, the enrollment of students in private, charter, virtual, and home schools had grown to $6.7 \%$ of Alberta's students (Calgary Board of Education, 2007), and the numbers are growing.

In particular, the locations of charter schools in Alberta have a noticeable pattern, with new schools appearing mainly in the province's urban centers. All thirteen of Alberta's charter schools are located in urban centres, with a total enrolment of 7000 students, 80 percent of them in the city of Calgary (Sadava, 2010, p. 29). There has been extensive scholarly and public debate about school choice issues (for examples, see: Bosetti, 2005; Brantlinger, 2003; Dingerson, Miner, Peterson, \& Walters, 2008; Sadava, 2010). Much of the literature has focused on the extent of school choice as it relates to the fulfillment of promises, typically only implicitly addressing issues related to social justice and school culture. As James (2003) asserts, people from dominant cultural groups, whether based on ethnic, racial, linguistic, economic, or other identity markers, "come to realize that they have a privileged and prestigious position in society, and, as a result, access to all the social, political and economic institutions within that society" (p. 102). In the case of education, parents from dominant groups have demanded specific alternative programs or charter schools to benefit their children. Apple (2004) notes that "charter schools and their equivalents.... tend to attract parents who live and work in relatively privileged communities" (p. 27). Inside this important and contentious ongoing discourse, the researcher located a charter school that had created a very promising course of study with a focus on social justice education.

\section{The Human Condition Course}

Students enrolled in this unique social justice education course, entitled The Human Condition, focused on the inequities people experience on the basis of their social group memberships, and through systems of constraint and advantage reproduced through marginalization, cultural inequities, and racism. Developed by educators from Crestview Charter School ${ }^{2}$ in 2005 and formally approved in 2006, the course is offered at the $10^{\text {th }}, 11^{\text {th }}$, and $12^{\text {th }}$ grade levels, and pays attention to the resources that individuals, families, and communities bring to personal and social change and to the transformation of educational institutions. According to the school's documents:

The Human Condition courses provide a continuum of knowledge, skills, and attitudes in the area of social, economic, and environmental factors that influence the Human Condition well beyond the introductory issues outlined in Social 10, 20, 30. The courses will: a) provide an opportunity for students to explore and immerse themselves in meaningful activities within the realm of Human Rights; b) enable students to develop a firm grasp of human rights, 
protection systems, international law, and factors that influence the human condition such as the environment, the economy, and culture; and c) provide students with an opportunity to become involved in leadership and volunteer activities in areas of human rights and environmental sustainability.

Topics covered in the course during this study included anti-Semitism and the Holocaust, genocide in the contexts of Rwanda and Darfur, nutritional needs in developing nations, sexism, nuclear proliferation, international relations, education and sustainability in developing nations, racism, ecological sustainability, sexism, and human rights, among others. Specific issues explored across social justice topics included analyzing the veracity of published sources, the use of technology, the role of the media, the functions and limitations of government, versions of democracy, youth leadership, and a host of others.

Teachers encouraged students to honor the complexity of the issues and their ongoing broad relevance. They adopted an inquiry-based approach to the course, including drafting a clearly established protocol for formulating questions, hypotheses, learning needs, and research sources and techniques. Students were also encouraged to take action as a result of their research into specific topics. In addition, the school organized their participation in a number of community events and fund-raisers, school-wide projects, and the school year culminated in an overseas student trip to engage in community development and education in a South American country.

The Crestview Charter School has its own board, but in its jurisdiction is considered a public school and is fully funded-except for student transportation grants - by its provincial ministry of education. This course is part of an expanded social justice education focus at this urban high school that has a mandate to serve gifted and above-average learners. As was outlined above, there has been extensive scholarly and public debate about school choice issues centering around charter schooling, particularly related to access and equity concerns. These issues are addressed in greater detail elsewhere (see Ball \& Lund, 2010; Lund \& Veinotte, 2010). On the positive side, this collaboration has helped form a reciprocal partnership - between the public school system, the Metropolis project and the university - that has been mutually beneficial, and can inform ongoing policy development as well as more theoretical understandings of social justice.

\section{Data Gathering and Analysis}

The researcher formulated guiding but flexible research questions generated from experiences and ongoing research in this field. Seeking a respectful engagement with the everyday social justice education of the participants, the researcher adopted features of a critical ethnographic approach (Carspecken, 
1996) adapted based on ongoing research experience (Lund, 2003, 2006; Lund \& Nabavi, 2008). While paying deliberate attention to the researchers' own values and assumptions, the study has sought to understand participants' perspectives in their own terms through a collaborative interview process.

The researcher is a former high school teacher with over two decades of organizing and studying school social justice projects, and the research assistant is an educator with substantial experience in social justice projects and who was enrolled in graduate studies full-time during the data-gathering phase of the project. During the initial phases, the researcher and research assistant gained institutional permissions and organized regular visits and interviews with the students, teachers, and administrators involved with the social justice course. As two White anti-racism educators, we attempted to foreground and interrogate our own limited perspectives and sought to honor the spirit of the question posed in Osterling and Wong (2008), "What does it mean to be an anti-racist ally?" and broaden it to include other forms of oppression.

Both the current teacher leading the social justice course under study and the school administration interviewed have been highly supportive of this collaborative research. This was an ideal situation conducive to rich data gathering and the development of a healthy and collaborative research environment. In addition, the insights gained from this research hold considerable promise in informing future course development in social justice that could be adopted by schools across the wider public school boards and beyond. Specific guiding themes for this project were identified from earlier studies and included examining how school practitioners plan curriculum, negotiate administrative support, use innovative technologies, and foster interest and commitment among students.

A series of field observations were conducted over the course of five months - near the beginning, middle, and near the end of one semester of the course. In addition, in-depth collaborative interviews were conducted with two teachers, Cornelius and Charlie $^{2}$ (who was also an administrator), and six students, following protocols of critical ethnography (Carspecken, 1996). Efforts were made to sample a diverse mix of students. The researchers gathered site observation data, field notes and documents, and transcribed, coded, and analyzed interviews. Follow-up communication with selected research participants was conducted to verify and, if necessary, clarify their accounts and understandings.

\section{Emerging Results}

Over the several months of visiting the school, observing classes, and interviewing student and teacher participants in The Human Condition course, the researchers were able to identify several key themes related to the success of 
the course in fostering an awareness of social justice. A more detailed accounting and analysis of the student and teacher responses will appear in the full final report of the study. The participants identified a number of strengths of the course, including the comprehensive nature of the information surveyed, the strong theme of student involvement, the complexity of understanding in current social justice issues, the fostering of informed opinions, the appropriateness of the course to their interests and strengths, and the inquiry approach taken by the teachers.

Further, the students appreciated the newfound responsibility and incentive to make positive changes in themselves and the world, including grassroots activism, school-wide projects, raising awareness in the community, and school-organized trips to youth conferences and to conduct humanitarian work overseas. Desiree, a 15-year-old student said, "It's interesting, once that course came into the school, instead of talking about other stuff at lunch time we'd be talking about actual issues-like talking about global warming during lunch hour. We have little debates in the middle of the hallways; it's actually quite humorous." During the semester following his teaching of the course, Charlie reported what he found most rewarding about it: "Even now, the course has been over for two and a half or three months, and kids are still coming up and talking to me about this stuff all the time, and so, I think that there's a segment of the population that finds these things intriguing, and if you can get [the students] with it then it's really, really impressive." Having the students internalize the message that their own analysis and actions can make a difference, influence public policy, and generally lead to solutions to complex problems seemed to be a strong motivator for the students and teachers alike.

Several of the students identified the qualities they appreciate in a teacher of a course such as this; they recommended that the teacher take a central role in the class, adding personal thoughts and views while remaining as neutral as possible. When asked what he thought were his teacher's strengths in the course, 16-year-old Alex replied: "I talk to him all the time I guess. But just really the way he ran the course, he took a really active role, and added his own things in while trying to stay impartial." Their teacher, Cornelius, described his own role as "not to give them concrete information, but rather, to give them the continual provocation - so whatever the video clip is, the reading, I think it's all related, but it's not obvious." He said he liked to encourage students to study the complexity of social and political issues. His perspective was, although students "can maybe sense where you stand on a lot of the issues, even though you try to be neutral, I am hoping that they get to see shades of grey."

This teacher's approach was to attend thoughtfully to the nuances of human rights and equity issues, using the example of racism: 
The reason why it's a problem is because it's complex-if something isn't complex it's not a problem right-it's resolved, it's very simple to deal with, and it disappears. If it doesn't disappear, then that means that there is something inherently problematic about it, and that means that there has to be complexity to it. To take a black or white view on these issues really means that you're missing half of the information.

Most students reported they appreciated that their teacher had obviously invested a great deal of time into planning and preparing the course activities and background materials, showing a high level of commitment and dedication. They also noted that Cornelius had an abiding passion for the course content, and a personal interest in fostering social justice.

Particularly helpful for the students interviewed was the inquiry-based learning approach employed throughout the school year. Rather than telling students what they needed to know, Cornelius would find resources in the library, popular media, and online; Alex describes that "sometimes he found a website where there were a whole bunch of big-name people... like environmentalists or activists, and they were interviewed for five minutes." In one lesson we observed, students were invited to watch a recorded YouTube interview with Noam Chomsky on globalism before working in groups on social justice-themed class projects. Greg, a 16-year-old, described how Cornelius' lessons incorporated both discussion and time for research:

Half the class we'd just be talking about this new reading that he'd found somewhere and just discussing it in class, and then we'd go off to do our own research which really helped, because we all got a sense of each other's ideas; [the research] exposed us to ideas other than our own on the same topic.

In addition, students had a great deal of flexibility and guidance in selecting specific topics for in-depth exploration through their major assignments and activist projects.

It is noteworthy that both Cornelius and Charlie, the teacher and teacher/administrator we interviewed, took part in designing and seeking provincial approval for The Human Condition course and were pleased with how it had unfolded with the students. They both specifically noted the projectbased approach and inquiry model of instruction, and their own key roles in facilitating the discussions and research while provoking further study and consideration of complex issues. Charlie said:

I think that is what makes it work, and I got a lot of feedback from the kids and they really liked the style. Basically, the deal with problem-based learning is that you don't present them with problems; you present them with scenarios and the scenarios need to be designed so that you capture all of the content... 
The philosophy is to not feed them information but to have them discover the questions and find the information themselves.

They also noted that there was a strong guiding curriculum for the course but with no standardized examination at the end, leaving more room to explore and discuss issues with fewer time constraints. They reported that, because most students had chosen to take the course as an option, this helped ensure a greater level of engagement and participation. Desiree mentioned the altruism among students that can fuel activism: "if [teachers] catch us now, we really do have a caring inside of us that isn't stifled yet, because we can't just look at things and say 'Well that's the way it is,' but 'What can I do about it?' and that's why this course is so important." Tackling the structural and economic barriers behind inequity and oppression remains challenging work, but these students were learning that this is necessary for students to become aware of the depth and scope of social issues. Both teachers said that these students were at an ideal age to explore these serious social issues, and that their idealistic sense of justice served them well in pursuing ambitious and provocative approaches to their projects.

A relatively small number of limitations of the course were noted, including there being no formal textbook available that ideally suits the content at this level. This requires a great deal of advance planning on the part of the teacher. In addition, there is a relatively heavy reading load for both teachers and students; there is an effort underway to reduce the use of paper in the course, considering the high profile that environmental and ecological issues has had in the course. With the proliferation of online resources and electronic media and literature, this goal seems attainable. The teachers also noted that the culminating overseas class trip was a bonus of the students' enrolment in the course but should not be used as an incentive, as it may attract students who are not as dedicated to the issues. Further, it may highlight issues around social class and access even with a range of bursaries and fundraisers to assist students from families with limited resources. Our research was admittedly limited by the nature of the relatively narrow number of the students we interviewed; future research including participants of a wider range and number of students would add richly to the data, as would those from different models and programs of study.

\section{Conclusion}

These preliminary results may offer a helpful focal point for understanding some of the ways teachers can plan - and how students experience-social justice education, building toward a grounded understanding of how human rights and equity are lived and experienced in the world. The results also suggest specific 
ways teachers can help locate and analyze human rights issues, and work toward equity and social justice through thoughtful curriculum and pedagogy in schools. Specifically, these school practitioners and their students shared insights around planning a meaningful curriculum, negotiating administrative support, and using online resources to foster a greater level of engagement and educational commitment among students. They reported on the traits and pedagogical stance that were most likely to help students take ownership of pressing global and local equity issues and to plan initiatives of their own to foster social justice.

The fact that this study took place within a publicly funded charter school is significant and points to the need to open up meaningful educational opportunities for students in all schools. Finding the balance between educational equity and school choice is an ongoing concern, but one that many educators and administrators strive toward. This work must be both political and personal and requires a complex balancing of needs through a critical interrogation of issues of power, race, class, gender, and other issues. Hopefully this study provides some initial guidance for negotiating and working within models of choice in public school cultures that intentionally foreground social justice issues.

Insights from this program can guide further social justice studies in educational research and curriculum development. The responses of students to inquiry projects and problem-based learning models may inform educational policy development related to school activism, human rights curricula, and collaborative social justice projects. Some previous research has focused more directly on the needs of particular marginalized students; this project generates knowledge about how teachers and students may formulate and take action on social justice initiatives through a specially designed high school course. I hope the findings generated may serve as a conceptual guide for practitioners and administrators wishing to shape effective multicultural and anti-racism strategies and initiatives; the voices from these students and teachers can encourage their role as agents in eliminating oppression and fostering social justice through innovative educational programs and curriculum. 


\section{Notes}

1. This research was supported by the Social Sciences and Humanities Research Council through a research grant from the Prairie Metropolis Centre. The Metropolis Project (http://www.metropolis.net) is an international network for comparative research and public policy development on migration, diversity, and immigrant integration in cities in Canada and around the world. Earlier findings from this study were presented at a national Metropolis conference (Lund, 2008a; Veinotte, 2008). The author is grateful for the capable assistance of research assistant, Cheryl Veinotte, throughout the study.

2. All participant names used in this paper are pseudonyms.

\section{References}

Alberta Education. (2007). School choice. Alberta Education web site. Retrieved August 14, 2010, from http://education.alberta.ca/parents/choice.aspx

Apple, M.W. (2004). Creating difference: Neo-liberalism, neo-conservatism and the politics of educational reform. Educational Policy, 18(1), 12-44.

Armstrong, D.E., \& McMahon, B.J. (Eds.). (2006). Inclusion in urban educational environments: Addressing issues of diversity, equity, and social justice. Greenwich, CT: Information Age.

Ball, D.A., \& Lund, D.E. (2010). School choice, school culture and social justice: A Canadian case study. Journal of Contemporary Issues in Education, 5(2), 3652.

Banks, J.A., McGee Banks, C.A., Cortés, C.E., Hahn, C.L., Merryfield, M.M., Moodley, K.A., Murphy-Shigematsu, S., Osler, A., Park, C., \& Parker, W.C. (2005). Democracy and diversity: Principles and concepts for educating citizens in a global age. Seattle, WA: University of Washington, Center for Multicultural Education.

Bosetti, B.L. (2005). School choice: Public education at a crossroad. American Journal of Education, 111(4), 435-441.

Brantlinger, E. (2003). Dividing classes: How the middle class negotiates and rationalizes school advantage. London, UK: RoutledgeFalmer.

Calgary Board of Education. (2007). Program choices. Calgary Board of Education web site. Retrieved August 14, 2010, from http://www.cbe.ab.ca/programs/progchoice.asp

Carspecken, P.F. (1996). Critical ethnography in educational research: A theoretical and practical guide. New York, NY: Routledge.

Cochran-Smith, M. (2004). American Educational Research Association: 2005 Annual meeting call for proposals. Educational Research, 33(4), 21-33.

Dei, G.J.S., \& Calliste, A. (2000) Mapping the terrain: power, knowledge and anti-racism education. In G.J.S. Dei \& A. Calliste (Eds) Power, knowledge and anti-racism education: a critical reader (pp. 11-22). Halifax, Nova Scotia, Canada: Fernwood. 
Dingerson, L., Miner, B., Peterson, B., \& Walters, S. (Eds.). (2008). Keeping the promise? The debate over charter schools. Milwaukee, WI: Rethinking Schools.

Gillborn, D. (2005). Racism in educational sites: Sustaining oppression and maintaining the status quo. In L. Karumanchery (Ed.), Engaging equity: New perspectives on anti-racist education (pp. 99-114). Calgary, Alberta, Canada: Detselig.

Gorski, P.C. (2004). Multicultural education and progressive pedagogy in the online information age. Multicultural Perspectives, 6, 37-48.

James, C.E. (2003). Seeing ourselves: Exploring race, ethnicity and culture ( $3^{\text {rd }}$ ed.) Toronto, Ontario, Canada: Thompson.

James, C.E. (Ed.). (2005). Possibilities and limitations: Multicultural policies and programs in Canada. Winnipeg, Manitoba, Canada: Fernwood.

Joshee, R. (2003). Citizenship and multicultural education in Canada: From assimilation to social cohesion. In J. A. Banks (Ed.), Diversity and citizenship education: Global perspectives (pp. 127-156). San Francisco, CA: Jossey-Bass.

Kumashiro, K.K. (2009). Against common sense: Teaching and learning toward social justice $\left(2^{\text {nd }}\right.$ ed.). New York, NY: Routledge.

Luchtenberg, S. (2003). Ethnic diversity and citizenship education in Germany. In J.A. Banks (Ed.), Diversity and citizenship education: Global perspectives (pp. 245271). San Francisco, CA: Jossey-Bass.

Lund, D.E. (2003). Facing the challenges: Student antiracist activists counter backlash and stereotyping. Teaching Education Journal, 14, 265-278.

Lund, D.E. (2006). Rocking the racism boat: School-based activists speak out on denial and avoidance. Race, Ethnicity and Education, 9(2), 203-221.

Lund, D.E. (2008a, April). Examining benefits and challenges of social justice research projects with youth. Paper presented at the $10^{\text {th }}$ Annual National Metropolis Conference, Halifax, Nova Scotia, Canada.

Lund, D.E. (2008b). Harvesting social justice and human rights in rocky terrain. The Ardent Anti-Racism \& Decolonization Review, 1(1), 64-67.

Lund, D.E., \& Nabavi, M. (2008). Understanding student anti-racism activism to foster social justice in schools. International Journal of Multicultural Education, 10(1), 1-20. Retrieved August 1, 2010, from http://ijmejournal.org/index.php/ijme/issue/current

Lund, D.E., \& Veinotte, C. (2010). Researching a social justice course in a charter school: A duoethnographic conversation. In Education: Exploring Our Connective Educational Landscape, 6(2). 34 paragraphs. Retrieved November 30, 2010, from http://www.ineducation.ca/article/researching-social-justicecourse-charter-school-xfduoethnographic-conversation

Nieto, S., \& Bode, P. (2007). Affirming diversity: The sociopolitical context of multicultural education ( $5^{\text {th }}$ edition). New York, NY: Allyn \& Bacon.

Osterling, J.P., \& Wong, S.D. (2008). Dangerous discourses and uncomfortable silences. Praxis: The Journal of Praxis in Multicultural Education, 3(1), 3-16.

Sadava, M. (2010, September). More choice, less education. Alberta Views, 13, 26-30.

Sleeter, C.E. (1996). Multicultural education as social activism. Albany, NY: SUNY Press. 
Solomon, R.P., \& Levine-Rasky, C. (2003). Teaching for equity and diversity: Research to practice. Toronto, Ontario, Canada: Canadian Scholars' Press.

Veinotte, C. (2008, April). Social justice education in public and charter schools. Paper presented at the 10th Annual National Metropolis Conference, Halifax, Nova Scotia, Canada.

Watkinson, A.M. (1999). Education, student rights and the Charter. Saskatoon, Saskatchewan, Canada: Purich. 


\section{National Association for Multicultural Education (NAME)}

\section{Mission Statement}

NAME is committed to a philosophy of inclusion that embraces the basic tenets of democracy and cultural pluralism. NAME celebrates cultural and ethnic diversity as a national strength that enriches a society and rejects the view that diversity threatens the fabric of a society. NAME believes that multicultural education promotes equity for all regardless of culture, ethnicity, race, class, language, age, gender, sexual orientation, disabilities, or religion. Thus, fair and full participation in a society's institutions is paramount as both means and end in NAME's philosophy. Xenophobia, discrimination, ethnocentrism, sexism, racism, ageism, classism, ableism, and homophobia are societal phenomena that are inconsistent with the principles of democracy and lead to the counterproductive reasoning that differences are deficiencies. NAME believes that multicultural education enables the individual to believe in one's own intrinsic worth and culture, to transcend monoculturalism and, ultimately, to become multicultural. This developmental process is at the center of the individual's noble quest to define one's relationship and responsibility to our global society. NAME recognizes that individuals have not always been, and perhaps never will be, in complete agreement regarding the definitions and goals of multicultural education and that continuing debate is healthy. 
Journal of Praxis in Multicultural Education 2011, 6(1), 93.

(c) 2011 The Center for Multicultural Education; The University of Nevada, Las Vegas

\section{NAME Regional Directors}

If you are interested in becoming involved in NAME activities at the state or regional level, please contact the appropriate person listed here:

Region One: Connecticut, Maine, Massachusetts, New Hampshire, Rhode Island, Vermont
Patty Bode

Tufts University

The School of the Museum of Fine Arts

Boston, MA

(617) 369-3613

patty.bode@ tufts.edu
Region Two: New Jersey, New

York, Puerto Rico, Virgin Islands
R. Deborah Davis

State University of New York at Oswego

Oswego, NY

(315) 312-2652

rddavis@oswego.edu

\footnotetext{
Region Three: Delaware, Tchet Dereic Dorman

District of Columbia, Maryland, Pennsylvania, Virginia, West Temple University Virginia Philadelphia, PA (215) 204-5509 Cell (215) 307-6041 tchet@temple.edu
}

Region Four: Alabama, Florida, Currently vacant

Georgia, Kentucky, Mississippi, North Carolina, South Carolina, Tennessee

\begin{tabular}{ll}
\hline Region Five: Illinois, Indiana, & Robin Brenneman \\
Michigan, Minnesota, Ohio, & Hilliard, OH \\
Wisconsin & (614) 527-4407 \\
& kenrob@ columbus.rr.com
\end{tabular}


Region Six: Arkansas, Louisiana, New Mexico, Oklahoma, Texas
Aretha Faye Marbley

Texas Tech University

Lubbock, TX

(806) 742-1997 x268

aretha.marbley@ttu.edu

Region Seven: Iowa, Kansas, Omiunota Ukpokodu

Missouri, Nebraska

University of Missouri-Kansas City

Kansas City, MO

(816) 235-2469

ukpokodun@umkc.edu

Region Eight: Colorado,

Montana, North Dakota, South

Dakota, Utah, Wyoming
Charlene Lui

Granite School District

Salt Lake City, UT

(801) 646-4205

clui@graniteschools.org

Region Nine: Arizona,

Currently vacant

California, Nevada

Region Ten: Alaska, Hawaii, Idaho, Oregon, Washington, American Samoa, Guam, Northern Mariana Islands, Trust Territory of the Pacific
Bette Tate Beaver

2716 226th Avenue NE

Sammamish, WA 98074

(206) 660-7154

mail4btb@aol.com 